\title{
Sedentary and Physical Activity Patterns in Adults with Intellectual Disability
}

\author{
Guillermo R. Oviedo ${ }^{1,2, *}$, Noémie Travier ${ }^{3}$ and Myriam Guerra-Balic ${ }^{1}$ \\ 1 FPCEE-Blanquerna, University Ramon Llull, 34 Císter Street, 08022 Barcelona, Spain; \\ miriamelisagb@blanquerna.url.edu \\ 2 Physical Activity, Sport and Recreation Research Focus Area, Faculty of Health Sciences, \\ North-West University, Potchefstroom 2520, South Africa \\ 3 Unit of Nutrition and Cancer, Catalan Institute of Oncology (ICO-IDIBELL), L'Hospitalet de Llobregat, \\ 08907 Barcelona, Spain; ntravier@iconcologia.net \\ * Correspondence: guillermorubeno@blanquerna.url.edu; Tel.: +34-932-533-000
}

Received: 7 July 2017; Accepted: 6 September 2017; Published: 7 September 2017

\begin{abstract}
Little is known about the patterns of sedentary time (ST) and physical activity (PA) levels throughout the week among adults and older adults with Intellectual Disability (ID). We analyzed ST and PA patterns of adults and older adults with ID. Forty-two adults and 42 older adults with mild to severe ID participated in this study. Height and weight were obtained to calculate Body Mass Index (BMI). Body fat and fat-free mass percentages were also obtained. Patterns of PA levels and ST were assessed with GT3X Actigraph accelerometers. Adults performed higher amounts of total PA and moderate to vigorous PA than older adults during the week, on weekdays and in center time (all $p>0.05$ ). No differences between males and females were found for either PA levels or ST. Only $10.7 \%$ of the participants met the global recommendations on PA for health. The participants of the current study showed low PA levels and a high prevalence of ST. Interestingly, when comparing age and/or sex groups, no differences were observed for ST. Our findings provide novel and valuable information to be considered in future interventions aiming to increase PA levels and reduce ST.
\end{abstract}

Keywords: intellectual disability; physical activity; sedentarism; ageing; accelerometer

\section{Introduction}

The lack of physical activity (PA) and the increase of sedentary behaviours among the general population have shown a direct relation with negative health outcomes $[1,2]$. For this reason many health guidelines published by several health authorities recommend regular PA to prevent health impairments [3,4].

There is a need to better understand PA levels, its nature and its relation to several health indicators. That is why researchers create and improve the tools used to quantify PA levels in different populations [5,6]. As previous studies have already shown over the few last years, numerous instruments have been developed to objectively measure PA levels. Accelerometers are used to objectively monitor PA, and lately, their use in different populations has increased [6,7]. There are studies that have effectively used these motion sensors with participants with intellectual disability (ID) to assess sedentary time (ST), PA levels and energy expenditure [8-11].

The Sedentary Behaviour Research Network has defined sedentary behaviour as activities with energy expenditures $\leq 1.5$ metabolic equivalents (MET) while in a sitting or reclining posture during waking hours [12]. This behaviour is related to negative effects on health $[13,14]$. To counteract these effects, adults should get at least 150 min a week of moderate PA (MPA), which intensities are between 3 to 5.99 METs, or 75 min a week of vigorous PA (VPA) that correspond to intensities $\geq 6.00$ METs in order to obtain metabolic health benefits [15]. These activities should be in bouts of at least $10 \mathrm{~min}$ [4]. 
As specific PA guidelines for people with ID do not exist, the general population recommendations are the guidelines used. More recently, awareness has risen about the importance of breaking-up ST and sedentary bouts as it was found that breaking-up ST and decreasing sedentary bouts are independent factors related to health outcomes and activities of daily living [16-18].

Regular PA is essential for adults with ID [19] because they show low rates of PA, decreased cardiovascular fitness and, high incidence of obesity [20-22]. Also, people with ID suffer from an early aging process starting around age 40-50 [23,24]. This process causes an early appearance of physical health problems, musculoskeletal disability, visual and hearing problems, dementia, chronic illnesses, and can, therefore, affect the activities of daily living $[25,26]$. In Spain, adults with ID older than 45 years old are considered older adults because the frequency of suffering these illnesses are similar to people older than 65 years old without ID [27].

Emerging evidence suggests that adults with ID are less active than healthy adults without ID [11,28]. In their review, Temple et al. [22] concluded that almost two-thirds of adults with ID did not reach the minimum amount of PA that might provide health benefits. Other studies showed that approximately $17 \%$ to $21 \%$ of adults and older adults with ID achieved the recommended 10,000 steps per day $[29,30]$. Furthermore, different authors have shown that most of the waking time during the day was spent being sedentary [21,31,32]. The study by Dixon-Ibarra et al. [33] indicated that older adults with ID were less active than a younger group with ID and a group of older adults without ID. In addition, they reported that $6 \%$ of older adults with ID and $13 \%$ of younger adults with ID met the recommendations of moderate to vigorous PA (MVPA) and ST ranged from $60 \%$ to $65 \%$ of waking time.

Little is known about the actual patterns of ST, as well as the duration and breaks of this behaviour, and different studies [11,28] pointed out the necessity of further studies to better understand sedentary behaviours and PA levels in people with ID. Due to the increasing lifespan of people with ID [34,35], it is important to know the bout and patterns of PA and ST of adults and older adults with ID, because such data could be used to design and implement age-specific health promotion programs aimed at decreasing sedentariness and increasing PA levels.

As far as we know, there are no studies that examined the temporal patterning of ST and PA levels throughout the week in adults and older adults with ID. Therefore, the purpose of this study was to objectively assess the temporal patterning of ST and PA levels throughout the week of Spanish adults and older adults with ID using accelerometers. A secondary purpose was to analyze the potential age and sex differences in PA levels and ST patterns among adults and older adults with ID throughout the week.

\section{Materials and Methods}

\subsection{Study Design and Participants}

This cross-sectional study used a convenience sample from an Occupational Day Center for people with ID (Catalonia, Spain). At the Occupational Day center, participants perform activities like sewing cushion covers and rugs, arts and crafts, weaving baskets, computer work, watching TV or videos, reading, writing, cleaning and, gardening. A total of 60 adults $<45$ years old ( 32 males $/ 28$ females) and 56 older adults $\geq 45$ years old ( 35 males/ 21 females), with mild to severe ID from the center, were invited to participate in this study. The informed consent form to participate in this study was obtained from 40 women and 52 men ( $45 \pm 12$ years old; $79.3 \%$ of the invited participants) with mild $(n=30)$, moderate $(n=34)$ and severe ID $(n=28)$, and their parents/legal tutors as requested by the Spanish law.

After signing the informed consent form, the ID classification was obtained from the patients' medical records resulting that all the participants were diagnosed with mild to severe ID according to the Spanish National Government classification [36]. This classification of ID represents a combination of patients' level of intelligence quotient (IQ) and adaptive behaviour, and categorizes the percentage of 
disability (physical, intellectual and / or sensorial) in 5 degrees as follows: non-existent ( $0 \%$ ), border-line $(15-29 \%)$, mild (30-59\%), moderate ( $60-75 \%)$ and severe or very severe $(\geq 76 \%)$.

All participants presented ID, but in 72 participants we were not able to classify the ID etiology. The other 20 were diagnosed as Down syndrome $(n=13)$, West syndrome $(n=2)$, cerebral palsy $(n=2)$, Cornelia Lange syndrome $(n=2)$ and Microcephaly $(n=1)$. Among these 20 participants conduct disorder $(n=13)$; epilepsy $(n=3)$ and autism $(n=2)$ were also diagnosed.

\subsection{Procedures}

Before beginning the study two meetings were held with the participants and parents/legal tutors. During the first meeting, testing procedures, potential benefits, associated risks and the period of time required for the study were explained to the participants and parents/legal tutors. During the second meeting, the different assessments were carried out. A rigorous process and procedure of obtaining consent for the study was set out to allow participants to be fully informed, autonomous, and empowered to consent as part of the study. Participants and parents and/or legal guardians were provided with space and time to assent to participate in the study. All participants and parents and/or legal guardians signed an informed consent to participate. After signing the informed consent form, a health screening questionnaire was completed by each participant's parent(s) and/or guardian.

All participants were able to walk without aids and did not present motor impairments. Exclusion criteria included contraindications to exercise or presence of a physical disability that would not allow doing PA.

This study was approved by the Institutional Review Board of the University Ramon Llull and follows the Helsinki guidelines for ethical behaviour (Ethical code: 1112004P).

\subsection{Anthropometric Measures}

Height was measured to the nearest $0.1 \mathrm{~cm}$ by using a stadiometer (Seca 225, Seca, Hamburg, Germany). Weight was measured to the nearest $0.1 \mathrm{~kg}$ on a digital scale (Seca 861, Hamburg, Germany) with the subject wearing lightweight clothing and no shoes. Body mass index (BMI) was calculated as weight in kilograms divided by height in meters squared $\left(\mathrm{kg} / \mathrm{m}^{2}\right)$ and participants were categorised into normal weight (BMI < 25), overweight (BMI of 25-29.99), and obese (BMI $\geq 30$ ) [37]. Waist circumference (WC) was measured three times in a horizontal plane at the narrowest section between the hips and the bottom of the rib cage. Participants were categorised into normal or elevated WC (WC $</ \geq 88 \mathrm{~cm}$ in women and WC $</ \geq 102 \mathrm{~cm}$ in men) [37]. Chest, abdomen and thigh skinfolds thickness for men and triceps, suprailiac, and thigh skinfolds thickness for women were measured on the right side of the body by using a Holtain skinfold caliper (Holtain Ltd., Wales, UK) and following the International Society for the Advancement of Kinanthropometry guidelines [38]. To calculate body density, the equation of Jackson and Pollock [39] was used for men. For women the equation of Jackson, Pollock and Ward [40] was used. Body fat percentage (BF\%) was calculated using Siri's equation [41] and body fat-free mass percentage $(\mathrm{FFM} \%)$ was determined thereafter [42]. All measurements were taken three times by the same trained person and the mean of the two closest was used for the analysis (test-retest reliability score $r=0.95$ ).

\subsection{Physical Activity Measurement}

Physical activity was assessed by using the GT3X ActiGraph accelerometer (Firmware 4.4.0, ActiGraph $^{\mathrm{TM}}$, Fort Walton Beach, FL, USA) and data were downloaded with the ActiLife 6 Software (v.6.12.0., ActiGraph ${ }^{\mathrm{TM}}$, Fort Walton Beach, FL, USA). This model, released in 2009, detects steps differently than the AM7164 model, therefore, applying the process of censoring steps, may no longer be necessary if a pedometer-based comparison is required [43-45].

Participants and parents/legal guardians were provided with instructions on how to wear the accelerometer during all waking hours, its placement and wear time. The accelerometers were fitted to the participants' right hip and were collected 8 days later. The devices were not used while bathing, showering or swimming. 
Outcome variables were total physical activity (TPA) (counts. $\mathrm{min}^{-1}$ ), steps per day (steps. day $^{-1}$ ), and time spent (min.day ${ }^{-1}$ ) in sedentary (ST) (0 to 99 counts $\left.\min ^{-1}\right)$, light (LPA) (100 to 2019 counts $\left.\mathrm{min}^{-1}\right)$ and MVPA $\left(\geq 2020\right.$ counts $\left.\mathrm{min}^{-1}\right)$. Time in MVPA was determined by adding the minutes over the moderate intensity threshold. The intensity cutoff points were replicated from the National Health and Nutritional Examination Survey (NHANES) for adults over 18 years of age [46]. At the same time, accelerometer data were divided into week days (WD) (Monday-Friday) and weekend days (WeD) (Saturday and Sunday), and in center time (9 a.m. to 5 p.m.) and outside-center time (from 5 p.m. to 11:59 p.m.) on week days. Non-wearing time was defined as a period of 60 consecutive minutes of zero counts with an allowance for up to 2 min of counts between 1 and 100 .

The proportion of participants meeting WHO recommendations for PA was assessed by following the methodology described by Troiano et al. (2008) [46]. We have also organized steps per day within 4 categories [47]: (1)<5000; (2) 5000-7499; (3) 7500-9999; (4) 10,000-12,499; and (5) $\geq 12,500$.

Three further summary measures of ST were calculated per day and averaged over valid days: percentage of wear-day spent in ST; number of sedentary bouts (defined as a period of consecutive minutes where the accelerometer registers $<100$ counts. $\min ^{-1}$ ) and number of sedentary breaks (defined as at least $1 \mathrm{~min}$ where the accelerometer registers $\geq 100$ counts $\cdot \mathrm{min}^{-1}$ following a sedentary bout).

The necessary number of days determined through the literature to assess habitual PA is four (week and/or weekend) days [48-50]. Participants who did not meet these criteria were given a new period to wear the monitors. For inclusion in the analysis, each participant needed a minimum wear time of $10 \mathrm{~h}$ per day [46]. Eight participants ( 3 older adults; 5 adults) that correspond to the $8.7 \%$ of the recruited participants did not meet the accelerometer criteria to be included in the analysis.

\subsection{Statistical Analysis}

Descriptive statistics were obtained for all variables, including sex, age, weight, height, BMI, WC, body fat and fat-free mass \% and PA outcomes. Continuous variables are presented as means and standard deviation (SD), and categorical variables are presented as percentages. Chi-square tests were used to investigate differences in proportions between sex and age groups, while $t$-tests were used to compare means.

Linear mixed-effect models were used to evaluate the effect of age (adults vs. older adults), sex, time of the day (center time vs. outside-center time) and day of the week (WD vs. WeD) on ST and PA levels. The four variables age, sex, time of the day and day of the week were simultaneously introduced into the models as cofactors, as the log likelihood ratio tests previously performed to assess the possible interaction between age and sex were only found significant for MVPA. For this specific outcome, a stratified analysis was also performed. Linear mixed-effects models were used to address the facts that we had repeated measures (center time vs. outside-center time and week day vs. weekend) and unbalanced data. Indeed, since we used mixed models we did not have to exclude from the analysis the few individuals for whom the outcome variable was not available at one time point [51]. Finally, adjusted linear models were used to analyze differences in ST between sex and age groups, and BMI category.

All models were controlled for the differences in wear time during each period and all outcome variables were naturally log-transformed (Ln) before being used in the models. The critical values for statistical significance were assumed at an alpha level $\leq 0.05$. Statistical analyses were conducted by using the Statistical Package for the Social Sciences (IBM SPSS, v 22.0, Chicago, IL, USA).

\section{Results}

\subsection{Demographics and Descriptive Data}

A total of 84 participants ( 49 males and 35 females) were included in the analysis. The general characteristics of the participants are presented in Table 1. 
Table 1. Descriptive characteristics of the participants.

\begin{tabular}{|c|c|c|c|c|c|c|c|}
\hline \multirow{2}{*}{ Variables } & \multirow{2}{*}{$\begin{array}{c}\text { All } \\
n=92\end{array}$} & \multicolumn{2}{|c|}{ Sex } & \multirow[b]{2}{*}{$p_{1}$} & \multicolumn{2}{|c|}{ Age Groups } & \multirow[b]{2}{*}{$p_{2}$} \\
\hline & & $\begin{array}{l}\text { Males } \\
n=53\end{array}$ & $\begin{array}{c}\text { Females } \\
n=39\end{array}$ & & $\begin{array}{l}\text { Adults } \\
n=47\end{array}$ & $\begin{array}{c}\text { Older Adults } \\
n=45\end{array}$ & \\
\hline Age (year) & $44(12)$ & $45(11)$ & $43(13)$ & 0.576 & $35(7)$ & $54(6)$ & $<0.001$ \\
\hline Height $(\mathrm{cm})$ & $160.5(11.1)$ & $165.2(9.7)$ & $154.1(9.8)$ & $<0.001$ & $161.4(12.3)$ & $159.5(9.5)$ & 0.419 \\
\hline Weight (kg) & $73.8(14.3)$ & $71.9(111.7)$ & $76.3(17.1)$ & 0.385 & $70.8(14.0)$ & $76.9(14.2)$ & 0.044 \\
\hline BMI $\left(\mathrm{kg} / \mathrm{m}^{2}\right)$ & $28.9(6.5)$ & $26.4(3.9)$ & $32.2(7.7)$ & $<0.001$ & $27.2(4.4)$ & $30.7(7.7)$ & 0.009 \\
\hline Normal (\%) & 26.1 & 37.7 & 10.3 & $<0.001$ & 36.2 & 15.6 & 0.067 \\
\hline Overweight (\%) & 42.4 & 50.9 & 30.7 & & 34.0 & 51.1 & \\
\hline Obese (\%) & 31.5 & 11.4 & 59.0 & & 29.8 & 33.3 & \\
\hline $\mathrm{WC}(\mathrm{cm})$ & $94.0(15.7)$ & $92.7(11.8)$ & $95.8(19.7)$ & 0.347 & $88.4(12.1)$ & $99.8(16.9)$ & $<0.001$ \\
\hline Normal (\%) & 57.6 & 77.4 & 30.8 & $<0.001$ & 66.0 & 48.9 & 0.098 \\
\hline Elevated (\%) & 42.4 & 22.6 & 69.2 & & 34.0 & 51.1 & \\
\hline Body fat mass (\%) & $30.7(10.0)$ & $24.5(7.4)$ & $39.1(6.2)$ & $<0.001$ & $30.4(9.5)$ & $31.2(10.6)$ & 0.706 \\
\hline Body fat-free mass (\%) & $32.8(7.7)$ & $37.2(5.7)$ & $26.9(5.8)$ & $<0.001$ & $33.6(7.1)$ & $31.9(8.3)$ & 0.304 \\
\hline
\end{tabular}

The proportion of participants categorized as obese was higher in females than males $(p<0.001)$. Regarding WC mean values, no differences were found for sex. However, older adults presented significantly higher WC mean values than adults $(p<0.001)$. The proportion of females categorized as elevated WC was higher than males $(p<0.001)$. Males had significantly lower $\mathrm{BF} \%$ mean values and higher FFM\% mean values than females (all $p<0.001)$.

\subsection{Physical Activity and Sedentary Time Differences}

Sedentary time and PA outcomes throughout the week are shown in Table 2. Participants wore the activity monitor during $5.99 \pm 1.07$ days, of which $4.38 \pm 0.37$ days during WD and $1.61 \pm 0.60$ days during WeD. During accelerometer wearing time, participants spent more time in ST during WD than during $\mathrm{WeD}$, as well as during center time than during the outside-center time (all $p<0.001)$. Participants performed more LPA, MVPA, TPA and steps per day during WD than during WeD (all $p<0.001$ ). When comparing center time vs. outside-center time, participants engaged more LPA, MVPA and steps per day (all $p<0.050)$ when they were at the center.

Table 2. Patterns of sedentary time and physical activity throughout the week in adults and older adults with ID.

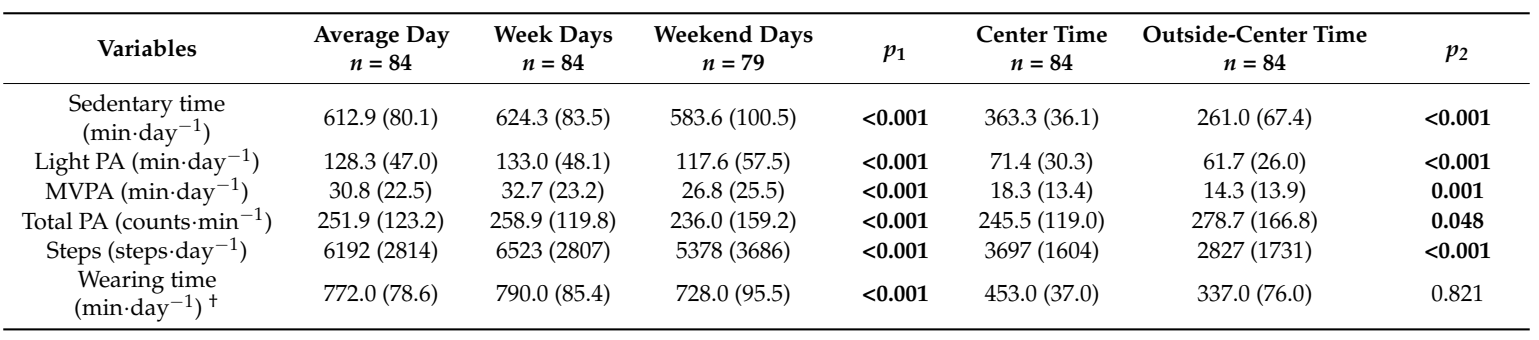

Note: the data presented above are raw means (SD). $p_{1}$ Differences between week days vs. weekend days based on mixed models adjusted for differences in wearing time, sex and age group. $p_{2}$ Differences between center time vs. outside-center time based on mixed models adjusted for differences in wearing time, sex and age group. ${ }^{\dagger}$ Differences based on mixed models adjusted for sex and age group. Statistically significant values are shown in bold $(p \leq 0.05)$. PA, physical activity; MVPA, moderate to vigorous physical activity.

Table 3 depicts PA outcomes during WD, WeD, center time and outside-center time by sex and age group. A main effect was detected for age group, where adults performed more MVPA and TPA during all week $(\mathrm{WD}+\mathrm{WeD})$ than older adults $(p=0.011 ; p=0.038)$. Adults performed more MVPA and TPA than 
older adults during WD ( $p=0.014$ and $p=0.042$ respectively). Also, during center time, adults performed more MVPA and TPA and had a higher step count than older adults (all $p<0.050)$. However, the differences in MVPA and TPA observed between adults and older adults with ID during WD were mainly due to the significant differences observed in men ( $p=0.0004 . ; p=0.013$ respectively). The differences in MVPA and TPA during center time were also only observed among men $(p=0.003 ; p=0.019$ respectively) (results not shown).

Table 3. Patterns of sedentary time and physical activity throughout the week in adults and older adults with ID by sex and age.

\begin{tabular}{|c|c|c|c|c|c|c|}
\hline \multirow[b]{2}{*}{ Variables } & \multicolumn{2}{|c|}{ Sex } & \multirow{2}{*}{$p$-Values } & \multicolumn{2}{|c|}{ Age Groups } & \multirow[b]{2}{*}{$p$-Values } \\
\hline & $\begin{array}{c}\text { Males } \\
n=49^{1}\end{array}$ & $\begin{array}{c}\text { Females } \\
n=35^{2}\end{array}$ & & $\begin{array}{l}\text { Adults } \\
n=42^{3}\end{array}$ & $\begin{array}{c}\text { Older Adults } \\
\quad n=42\end{array}$ & \\
\hline \multicolumn{7}{|l|}{ Average day $^{\dagger}$} \\
\hline Sedentary time $\left(\mathrm{min} \cdot \mathrm{day}^{-1}\right)$ & $607.7(86.0)$ & $620.2(71.6)$ & 0.369 & $599.7(76.8)$ & $626.0(82.2)$ & 0.155 \\
\hline Light PA $\left(\min \cdot\right.$ day $\left.^{-1}\right)$ & $130.5(54.4)$ & $125.2(34.7)$ & 0.922 & $121.8(39.9)$ & $134.8(52.8)$ & 0.247 \\
\hline MVPA (min. day $\left.{ }^{-1}\right)$ & $32.1(26.8)$ & $29.0(14.6)$ & 0.913 & $36.3(26.3)$ & $25.3(16.4)$ & 0.011 \\
\hline Total PA (counts $\cdot \min ^{-1}$ ) & $260.2(146.4)$ & $240.2(80.8)$ & 0.838 & $277.8(138.8)$ & $226.0(100.4)$ & 0.038 \\
\hline Steps (steps $\cdot$ day $^{-1}$ ) & $6389(3313)$ & $5916(1923)$ & 0.884 & $6539(2960)$ & $5844(2650)$ & 0.204 \\
\hline \multicolumn{7}{|l|}{ Weekdays $^{\dagger}$} \\
\hline Sedentary time $\left(\min \cdot\right.$ day $\left.^{-1}\right)$ & $623.1(89.1)$ & $625.9(76.3)$ & 0.641 & $608.4(77.9)$ & $640.2(86.9)$ & 0.396 \\
\hline Light PA $\left(\min \cdot\right.$ day $\left.^{-1}\right)$ & $132.5(52.8)$ & $133.8(41.5)$ & 0.512 & $127.8(43.7)$ & $138.2(52.2)$ & 0.502 \\
\hline $\operatorname{MVPA}\left(\mathrm{min} \cdot \mathrm{day}^{-1}\right)$ & $33.6(26.8)$ & $31.4(17.2)$ & 0.874 & $39.3(26.3)$ & $26.0(17.6)$ & 0.014 \\
\hline Total PA (counts $\cdot \min ^{-1}$ ) & $262.7(137.3)$ & $253.6(91.6)$ & 0.918 & $291.3(129.9)$ & $226.6(100.3)$ & 0.042 \\
\hline Steps (steps. day ${ }^{-1}$ ) & $6622(3222)$ & $6386(2133)$ & 0.920 & $7047(2970)$ & $5999(2564)$ & 0.146 \\
\hline \multicolumn{7}{|l|}{ Weekend days $^{\dagger}$} \\
\hline Sedentary time $\left(\min \cdot \mathrm{day}^{-1}\right)$ & $568.3(101.9)$ & $606.1(95.5)$ & 0.069 & $586.6(103.6)$ & $580.7(98.5)$ & 0.942 \\
\hline Light PA $\left(\mathrm{min} \cdot \mathrm{day}^{-1}\right)$ & $125.8(66.5)$ & $105.6(38.7)$ & 0.260 & $108.6(51.7)$ & $126.4(62.0)$ & 0.067 \\
\hline MVPA (min $\left.\cdot \mathrm{day}^{-1}\right)$ & $29.0(30.7)$ & $23.5(14.9)$ & 0.746 & $28.4(29.7)$ & $25.2(20.8)$ & 0.822 \\
\hline Total PA (counts $\cdot \min ^{-1}$ ) & $255.7(189.9)$ & $207.0(93.7)$ & 0.366 & $237.1(180.3)$ & $234.9(137.8)$ & 0.733 \\
\hline Steps (steps $\cdot$ day $^{-1}$ ) & $5787(4286)$ & $4777(2509)$ & 0.396 & $5211(3573)$ & $5540(3831)$ & 0.392 \\
\hline \multicolumn{7}{|l|}{ Center time $^{\dagger}$} \\
\hline Sedentary time $\left(\min \cdot \mathrm{day}^{-1}\right)$ & $363.8(41.2)$ & $362.5(27.9)$ & 0.976 & $362.6(29.1)$ & $363.9(42.3)$ & 0.853 \\
\hline Light PA $\left(\mathrm{min} \cdot \mathrm{day}^{-1}\right)$ & $70.3(33.3)$ & $72.9(25.9)$ & 0.388 & $69.7(25.8)$ & $73.1(34.5)$ & 0.300 \\
\hline MVPA (min $\cdot$ day $\left.^{-1}\right)$ & $18.0(13.9)$ & $18.8(12.8)$ & 0.469 & $22.6(14.0)$ & $14.0(11.3)$ & 0.001 \\
\hline Total PA (counts $\cdot \min ^{-1}$ ) & $242.1(125.5)$ & $250.3(110.8)$ & 0.558 & $277.6(119.9)$ & $213.4(110.3)$ & 0.017 \\
\hline Steps (steps $\cdot$ day $^{-1}$ ) & $3654(1714)$ & $3756(1457)$ & 0.617 & $4121(1517)$ & $3273(1593)$ & 0.047 \\
\hline \multicolumn{7}{|l|}{ Outside-center time $^{\dagger}$} \\
\hline Sedentary time $\left(\min \cdot\right.$ day $\left.^{-1}\right)$ & $259.3(70.7)$ & $263.4(63.3)$ & 0.231 & $245.8(68.7)$ & $276.2(63.3)$ & 0.473 \\
\hline Light PA $\left(\mathrm{min} \cdot \mathrm{day}^{-1}\right)$ & $62.1(25.9)$ & $60.9(26.5)$ & 0.992 & $58.1(28.5)$ & $65.1(23.0)$ & 0.242 \\
\hline MVPA (min $\cdot$ day $\left.^{-1}\right)$ & $15.6(16.5)$ & $12.6(9.1)$ & 0.409 & $16.6(17.9)$ & $12.0(7.8)$ & 0.066 \\
\hline Total PA (counts $\cdot \mathrm{min}^{-1}$ ) & $293.9(197.5)$ & $257.5(109.6)$ & 0.441 & $315.2(206.0)$ & $242.3(105.6)$ & 0.135 \\
\hline Steps (steps $\cdot$ day $^{-1}$ ) & $2967(1970)$ & $2630(1328)$ & 0.492 & $2927(2075)$ & $2726(1319)$ & 0.550 \\
\hline
\end{tabular}

When analyzing differences between WD vs. WeD, it was found that all participants were more sedentary during WD (all $p<0.010$ ). Regarding LPA and steps, all participants presented higher mean values during WD than during WeD (all $p<0.050)$. Males, females and adults performed more MVPA and TPA during WD than during $\mathrm{WeD}$ (all $p<0.050$ ).

When comparing center time vs. outside-center time all participants spent more time in ST during center time (all $p<0.001$ ). All participants performed greater amounts of LPA during center time than during outside-center time (all $p<0.050$ ). Adults and females performed greater amounts of MVPA during center time than during outside-center time $(p<0.001 ; p=0.001)$. On the other hand, males and older adults registered greater values of total PA during outside-center time than during center time (all $p \leq 0.050$ ). When comparing steps per day, all participants performed more steps during center time than during outside-center time (all $p<0.010$ ).

Figure 1 depicts the proportion of participants meeting WHO recommendations for $\mathrm{PA}$ ( $\geq 150 \mathrm{~min}$ per week of MVPA in 10-min bouts) and the percentage of participants within daily steps category. 
Overall, 9 (10.7\%) participants met PA recommendations and $9(10.7 \%)$ achieved 10,000 steps.day ${ }^{-1}$. When comparing by sex, 6 males $(12.2 \%)$ and 3 females (8.6\%) met the PA recommendation and 8 males $(16.3 \%)$ and only 1 female $(2.9 \%)$ achieved the recommended 10,000 steps. day ${ }^{-1}$, no significant differences were observed between sex. A total of 7 adults $(16.7 \%)$ and 2 older adults $(4.8 \%)$ met the PA recommendation while 4 adults $(9.5 \%)$ and 5 older adults $(11.9 \%)$ achieved the recommended 10,000 steps $\cdot$ day $^{-1}$. No significant differences were observed among adults and older adults.
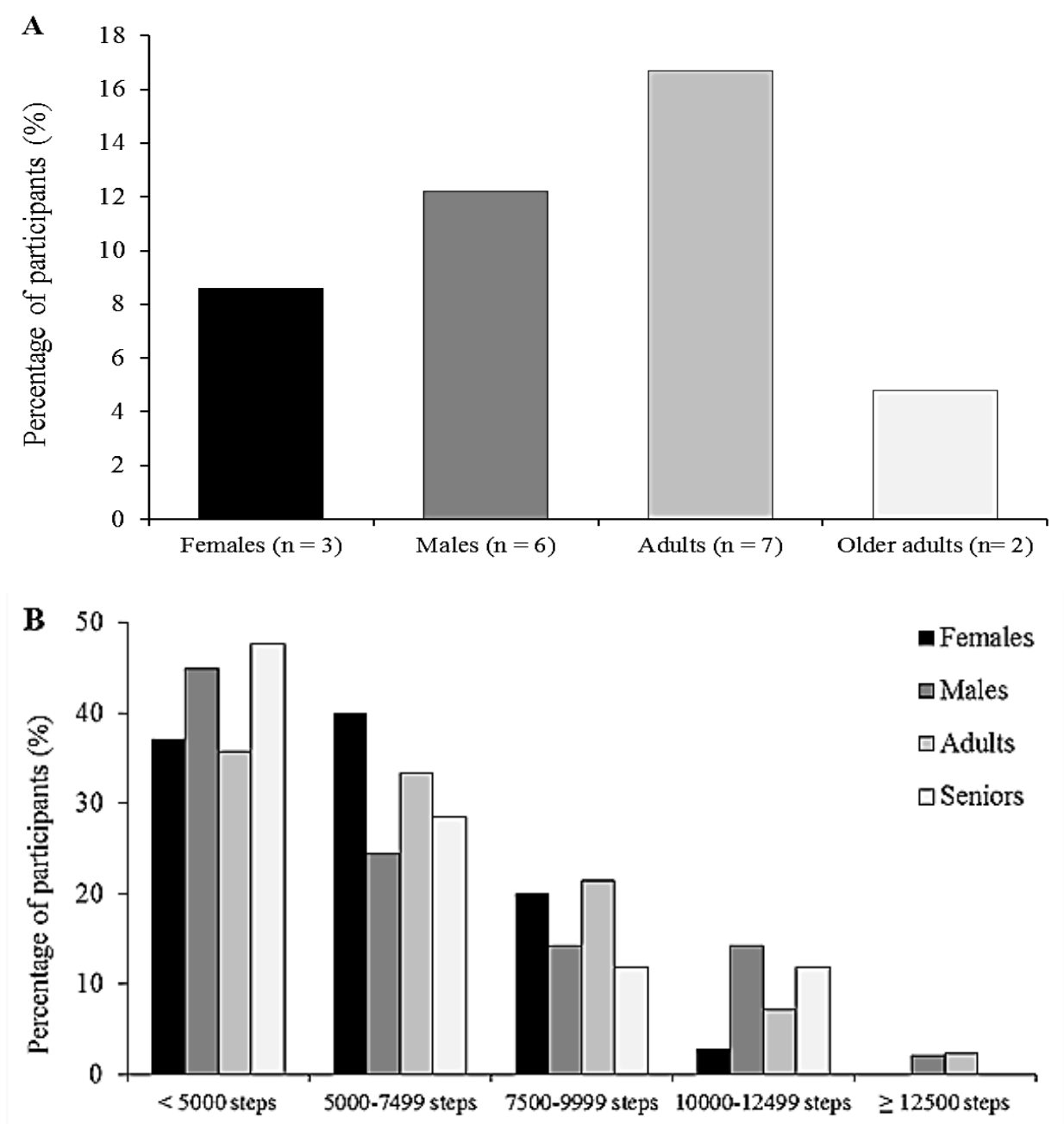

Figure 1. Percentage of participants who met the WHO recommendation for PA (A) and percentage of participants within daily step categories (B) by sex and age groups.

\subsection{Sedentary Time Patterns}

Table 4 presents the analysis for ST. In this study, the participants spent $79.4 \%$ of their waking time in ST. There were on average 65 sedentary bouts per day (lasting $6.0 \pm 1.3 \mathrm{~min}$ ) with on average 6 breaks per sedentary hour (lasting $6.7 \pm 3.1 \mathrm{~min}$ ). A significant difference was found for age groups where adults present a higher number of breaks per sedentary hour than older adults $(p=0.048)$ and the obese participants spent more time in ST than those participants with a normal BMI $(p=0.042)$. The number of bouts in sedentary behaviours per day was greater in participants classified as overweight and obese than in participants classified as normal weight $(p \leq 0.005)$. On average, the participants had 1 bout $\geq 30 \mathrm{~min}$ of ST per day, which accounted for $9.4 \%$ of ST, and only 0.3 bouts $\geq 60$ min of ST per day, which accounted for $4.5 \%$ of ST (Table 5 ). 
Table 4. Time in sedentary, percentage of sedentary behavior $\cdot$ day $^{-1}$, number of sedentary bouts $\cdot$ day $^{-1}$, and number of breaks per sedentary hour.

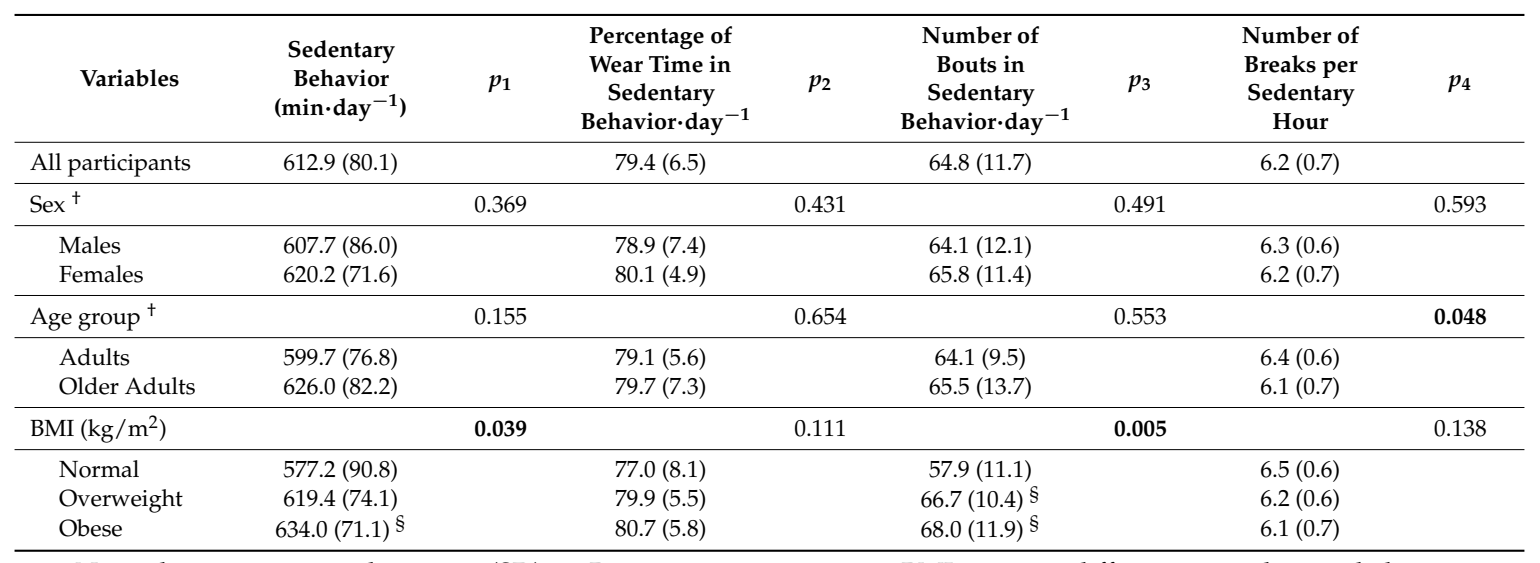

Note: data are expressed as mean (SD). $p_{1}$ Between age groups, sex, BMI category difference in sedentary behavior $\left(\right.$ min $\cdot$ day $\left.^{-1}\right) \cdot p_{2}$ Between age groups, sex, BMI category difference in sedentary behavior day $^{-1}(\%)$. $p_{3}$ Between age groups, sex, BMI category difference in the number of bouts in sedentary behavior $\cdot$ day $^{-1} \cdot p_{4}$ Between age groups, sex, BMI category difference in the number of breaks per sedentary hour. ${ }^{\dagger}$ Differences between age groups based on linear models adjusted for sex; differences between sex based on linear models adjusted for age group. $\S$ Significant difference $(p \leq 0.05)$ when compared to Normal BMI. Statistically significant values are shown in bold $(p \leq 0.05)$. BMI, body mass index.

Table 5. Number of sedentary bouts $\cdot$ day $^{-1}$, percentage of sedentary bouts and percentage of sedentary time of various bouts duration.

\begin{tabular}{cccc}
\hline Bout Duration (min) & $\begin{array}{c}\text { Number of Sedentary } \\
\text { Bouts per day }{ }^{\boldsymbol{t}}\end{array}$ & $\begin{array}{c}\text { Percentage of Sedentary } \\
\text { Bouts of } \boldsymbol{n} \text { } \mathbf{m i n} \S\end{array}$ & $\begin{array}{c}\text { Percentage of Sedentary } \\
\text { Time in Bouts of } \boldsymbol{n} \text { min * }\end{array}$ \\
\hline $2+$ & $64.8(11.7)$ & 100 & 100 \\
$5+$ & $23.8(7.0)$ & $36.3(8.6)$ & $65.8(11.2)$ \\
$10+$ & $9.0(3.9)$ & $13.8(5.7)$ & $39.7(12.5)$ \\
$20+$ & $2.6(1.6)$ & $4.0(2.7)$ & $18.6(9.9)$ \\
$30+$ & $1.0(0.8)$ & $1.6(1.4)$ & $9.4(6.8)$ \\
$40+$ & $0.6(0.4)$ & $0.9(0.8)$ & $6.6(4.8)$ \\
$50+$ & $0.4(0.3)$ & $0.6(0.5)$ & $5.1(3.5)$ \\
$60+$ & $0.3(0.2)$ & $0.5(0.3)$ & $4.5(2.4)$ \\
\hline
\end{tabular}

\footnotetext{
Note: data are expressed as mean (SD). ${ }^{\dagger}$ A bout of sedentary behavior is defined as a period of consecutive minutes where the accelerometer register $<100$ counts $\cdot \mathrm{min}^{-1} . \S$ Number of sedentary bouts of $n \mathrm{~min} /$ number of sedentary bouts of $2 \mathrm{~min} .{ }^{*}$ Length of sedentary bouts of $n \mathrm{~min} /$ length of sedentary bouts of $2 \mathrm{~min}$.
}

\section{Discussion}

The main finding of this study is that adults with ID perform more MVPA and TPA than older adults with ID, but no differences were found in ST. The results regarding MVPA and TPA are similar to those found in previous studies with general population and people with ID [31-33,46], where PA levels decrease with age. In addition, we found that adults with ID engaged in more MVPA and TPA than older adults with ID on WD and in center time. When the age group was divided by sex, it was found that the main differences in MVPA during WD and center time were due to the fact that adult males with ID perform more MVPA than older adults with ID. These results indicate that older males and females of the current study should be engaged in age and sex specific activities to increase their PA levels. Both sex and adults of the current study engaged in more MVPA, TPA and performed more steps during WD than during WeD. This is probably due to the fact that part of work tasks of the participants requires light to vigorous intensity physical labors such as cleaning and gardening.

Regarding the WHO recommendations on PA for health, $17 \%$ of adults and $\sim 5 \%$ of older adults in the present study achieved them. The value found for adults was higher than the value found by Dixon-Ibarra et al. [33] and similar to the values found in older adults with ID. When presented by 
sex group, $\sim 12 \%$ of males and $\sim 9 \%$ of females met the recommendation. Worryingly, in our study the percentage of people with ID achieving WHO recommendations was very low ( 11\%); nevertheless, this percentage is slightly higher than the percentage reported in the review by Dairo et al. [11] for people with ID (9\%) and higher than the values found for US adults without ID where less than $5 \%$ of them were achieving the recommended amounts of PA for health [46]. On the other hand, the percentage of participants achieving the recommendations are lower than those reported in 2010 by WHO where around $23 \%$ of adults aged 18 and over were not active enough.

The average time for MVPA found in our study $\left(\sim 31 \mathrm{~min} \cdot\right.$ day $\left.^{-1}\right)$ is higher than those presented by Melville et al. [8] ( $\left.\sim 3 \mathrm{~min} \cdot \mathrm{day}^{-1}\right)$ and similar to those obtained by Phillips \& Holland [32] $\left(\sim 36 \mathrm{~min} \cdot \mathrm{day}^{-1}\right)$. However, when dividing the sample by age groups, adults averaged $\sim 36 \mathrm{~min}$ of MVPA per day while older adults averaged $\sim 25$ min of MVPA per day. These values are higher than the results found by Dixon-Ibarra et al. [33] for adults and older adults with ID, which could be due to the different mean age of their groups, but are still lower than the values obtained in another study for a group of active adults without ID [21]. When splitting our data by sex, we found that the values of MVPA for males were lower than the values reported by Phillips et al. [32] and were similar for females. In the same line with another study [31] but in contrast with Phillips et al. [32], we found no differences for MVPA between sex. These differences between results could be explained by the age of the participants in the study by Phillips et al. [32], where the mean age was $~ 34$ years old while in the current study the mean age was 44 years old. Also, the fact that $100 \%$ of participants in the current study were attending a day center might have contributed to increase the MVPA performed by them.

The values of LPA found in our study were similar to the values reported by Phillips et al. [32] and higher than the values reported by Melville et al. [8]. The difference with Melville et al. [8] could be due to the fact that their participants were 4 years older than the participants in this study and all of them presented a BMI $\geq 30 \mathrm{~kg} / \mathrm{m}^{2}$.

Compared with another study assessing TPA in people with ID [32], we found that the TPA performed by the participants in this study was much lower. We hypothesised that this could be due to the older age of our participants and the lower amount of minutes spent in MVPA.

Overall, participants from this study accumulated more steps during WD and during center time. These differences could be due to different tasks that the participants performed at their work center (gardening, cleaning, tasks in the kitchen and cafeteria, etc.). During the $\mathrm{WeD}$, adults had a higher step counts than older adults, which might be due to age-related decrease of physical functioning or to the lack of motivation or opportunities for older adults with ID to be part of leisure activities during the WeD [52].

The average number of steps per day reported in the review by Dairo et al. [11] ( 6795 steps.day $\left.{ }^{-1}\right)$ is slightly higher than the average steps per day performed by our participants ( 6192 steps $\cdot$ day $^{-1}$ ). Also, the number of daily steps in the current study are lower than daily steps reported by Hansen et al. [53] for people without ID (8038 steps $\cdot$ day $^{-1}$ ). Moreover, in our study $\sim 11 \%$ of the participants achieved $\geq 10,000$ steps $\cdot$ day $^{-1}$ while $\sim 47 \%$ perform 5000 to 10,000 steps $\cdot$ day $^{-1}$ and $\sim 42 \%$ did not achieve 5000 steps $\cdot \mathrm{day}^{-1}$. When comparing with other studies, we found that the proportion of adults with ID that accumulated the recommended quantity of steps per day in our study was lower than the values reported by other authors, who found that $14 \%$ to $45 \%$ of participants achieved the recommendation [29,30,54], but higher than the proportions reported by Dixon-Ibarra et al. [33]. Also, our study shows that a small proportion of participants $(\sim 27 \%)$ performed the mildest criterion of 7500 steps $\cdot$ day $^{-1}$. This number of steps may maintain and promote health benefits to this specific population with ID [55].

When analyzing very sedentary population, such as people with ID, we hypothesize that the rule where only the accumulation of 150 min of moderate-intensity or 75 min of vigorous-intensity PA or some combination of the two per week in bouts of at least $10 \mathrm{~min}$ [4] will lead to health improvements may be very restrictive; and it might be possible that the accumulation of a volume of LPA and/or 
MVPA in bouts with a duration lower than 10 min might be less restrictive and really healthy PA [56]. Nevertheless, this hypothesis needs to be rigorously tested in future studies including people with ID.

The high level of sedentary activity and low adherence to PA recommendations found in our study are in concordance with the results found by several studies [8,32,33]. In general, adults and older adults from our study spent on average $\sim 79 \%$ of their non-sleeping time as sedentary, while only $\sim 17 \%$ and $\sim 4 \%$ of the monitored time were spent in LPA and MVPA, respectively. The proportion of time spent in sedentary behaviour is higher than the results presented by another study [33] where people with ID spent $\sim 61 \%$ of waking time in ST but in line with the review by Melville et al. [28] where ST range from $63 \%$ to $87.5 \%$. In the current study, the percentage of non-sleeping time spent in ST was higher than the $\sim 57 \%$ to $\sim 61 \%$ of non-sleeping time spent in ST by people without ID $[57,58]$. It is worth keeping in mind that the choice of accelerometer cut-off points may affect the time spent in ST. We re-analyzed our data with the cut-off points proposed by Aguilar-Farías et al. [59] and we found that the participants of the current study spent $\sim 66 \%$ of their non-sleeping time in ST.

When analyzing different periods of the week, we found that during accelerometer wearing time participants engaged in more ST during WD than WeD. In contrast to the results obtained by Dixon-Ibarra et al. (2013) [33] and independently of the period of the week (WD vs. WeD; center time vs. outside-center time), no differences between groups were found, which indicates that the problem of excessive time spent in ST is not dependent on the sex or age of the participants of the current study, but is a common behavioural pattern and, therefore, new strategies should be implemented in order to reduce this behaviour that is detrimental to their health.

Regarding the patterns of sedentary behaviour, $\sim 86 \%$ of sedentary bouts occurred at bout durations of $<10$-min of which $\sim 63 \%$ occurred at bout durations of $<5$-min and $\sim 23 \%$ occurred at bout durations between 5-min and 10-min. In this study, we found less sedentary bouts per day than other authors, but the duration was greater than the reported by these authors [60]. The number of sedentary breaks in this study is lower than the sedentary breaks carried out by old people without ID [60,61], indicating that the risk of suffering metabolic disorders is higher in people with ID due to an excessive time spent in sedentary and lower quantities of sedentary breaks [58].

Sedentary behavior is ubiquitous in modern life and people with ID, who already suffer from lack of places and opportunities to include PA as part of their lifestyle, are not exempt of this harmful behaviour. The amount of time that adults with ID are inactive is problematic, especially if participants were pursuing sedentary activity during the non-wear time. Fortunately for sedentary and low active populations, reductions in mortality risk begin to accumulate with the first increase in PA beyond base-line [62], which means that even small increases in activity could provide substantial health benefits.

Possibilities to engage in PA programs may be hindered due to many social, cognitive, motor and behavioural factors associated with the presence of ID. Low participation in PA programs for adults with ID may be related to lack of appreciation of the benefits of PA, lack of support from their caregivers or difficulty in finding experienced personnel to train them [63]. Assessing the barriers that people with ID face to be part of structured PA programs is essential to later be able to provide them with the most suitable opportunities in accordance with their ID levels and necessities.

Taking into account the results of the study by Dunstan et al. [64] showing that even short bout of interruptions in sedentary time with light or moderate intensity walking significantly reduced the levels of postprandial glucose and insulin; we consider that focusing on replacing sedentary behaviour by light PA rather than on accumulating bouts $\geq 10$-min of MVPA could be an achievable strategy to increase PA levels in people with ID.

A limitation of our study that should be highlighted is that PA may have been underestimated because ActiGraph accelerometers were mounted at the hip level and PA or movements with the upper-body were not measured. Also, these accelerometers cannot be worn during swimming or bathing activities. Cutoff points used in this study were developed for people without ID; therefore they might not be perfectly suitable to assess either PA or ST in population with ID. The cutoff points 
used to categorize PA intensity levels may underestimate energy expenditure and intensity in this population due to reduced coordination of movements, lower maximum oxygen consumption and increased mean weight $[65,66]$. In addition, the assigned work tasks in this specific center may be different to the general ID population; therefore, the levels of PA and ST of the participant of the current study might not be perfectly comparable with the rest of people with ID. Since multiple comparisons corrections were not applied in the present study in order to decrease the probability of getting false negative results due to the small size of the study, results of borderline significance need to be cautiously interpreted and will warrant confirmation in future studies. Finally, it is not possible to claim that our results are representative of the population of adults and older adults with ID because we have used a convenience sampling methodology to assessed PA levels and ST from one specific Spanish region.

\section{Conclusions}

This study provides novel and valuable detailed data on ST (number and duration of bouts, breaks and the total amount of ST) and PA patterns in a sample of adults and older adults with ID. It shows that PA levels of adults and older adults with ID involved in this study are very low and there is a high prevalence of sedentarism. The fact that only $10.7 \%$ of the participants met PA recommendations and/or achieved 10,000 steps.day ${ }^{-1}$ indicates that special attention should be paid to the creation of new strategies and well-designed and accessible health promotion programs for adults with ID, which must take into consideration the barriers that people with ID face to practice PA. These programs should focus not only on increasing PA levels but also on reducing sedentary levels.

On the other hand, future studies are needed to further investigate how PA levels and the excessive time spent in ST, bouts of particular duration and quantities of sedentary breaks are related to health outcomes and other risk factors of health in this unique population. These data and knowledge will help to target specific interventions to maintain their functional independence and provide opportunities for recreation and enjoyment that will help to improve their quality of life.

Acknowledgments: This work was partially supported by the Spanish Ministry of Economy and Competitiveness (I+D+i Ref: DEP2012-35335); the Autonomous Government of Catalonia, DEC's SUR (2013FI_B2 00091); the Spanish Ministry of Health (Instituto de Salud Carlos III RTICC RD06/0020/0091 and RD12/0036/0018). The cost to publish in open access was covered by the grant from the University Ramon Llull (2017-URL-Proj-040). The authors are very grateful to the participants for their willingness to take part in this research. We would also like to thank María Carbó-Carreté and Silvia Barnet-López for invaluable help in data collection.

Author Contributions: Guillermo R. Oviedo and Myriam Guerra-Balic conceived and designed the experiments; Guillermo R. Oviedo and Myriam Guerra-Balic performed the experiments; Noémie Travier and Guillermo R. Oviedo analyzed the data; Guillermo R. Oviedo, Noémie Travier and Myriam Guerra-Balic wrote the paper.

Conflicts of Interest: The authors declare no conflict of interest.

\section{References}

1. Biswas, A.; Oh, P.I.; Faulkner, G.E.; Bajaj, R.R.; Silver, M.A.; Mitchell, M.S.; Alter, D.A. Sedentary time and its association with risk for disease incidence, mortality, and hospitalization in adults. Ann. Intern. Med. 2015, 162, 123-132. [CrossRef] [PubMed]

2. Kohl, H.W.; Craig, C.L.; Lambert, E.V.; Inoue, S.; Alkandari, J.R.; Leetongin, G.; Kahlmeier, S. The pandemic of physical inactivity: Global action for public health. Lancet 2012, 380, 294-305. [CrossRef]

3. Garber, C.E.; Blissmer, B.; Deschenes, M.R.; Franklin, B.A.; Lamonte, M.J.; Lee, I.M.; Nieman, D.C.; Swain, D.P. Quantity and quality of exercise for developing and maintaining cardiorespiratory, musculoskeletal, and neuromotor fitness in apparently healthy adults: Guidance for prescribing exercise. Med. Sci. Sports Exerc. 2011, 43, 1334-1359. [CrossRef] [PubMed]

4. World Health Organization. Global Recommendations on Physical Activity for Health; World Health Organization: Geneva, Switzerland, 2010.

5. Yang, C.C.; Hsu, Y.L. A review of accelerometry-based wearable motion detectors for physical activity monitoring. Sensors 2010, 10, 7772-7788. [CrossRef] [PubMed] 
6. Ward, D.S.; Evenson, K.R.; Vaughn, A.; Rodgers, A.B.; Troiano, R.P. Accelerometer use in physical activity: Best practices and research recommendations. Med. Sci. Sports Exerc. 2005, 37, S582-S588. [CrossRef] [PubMed]

7. Chen, K.Y.; Bassett, D.R. The technology of accelerometry-based activity monitors: Current and future. Med. Sci. Sports Exerc. 2005, 37, S490-S500. [CrossRef] [PubMed]

8. Melville, C.A.; Boyle, S.; Miller, S.; Macmillan, S.; Penpraze, V.; Pert, C.; Spanos, D.; Matthews, L.; Robinson, N.; Murray, H.; et al. An open study of the effectiveness of a multi-component weight-loss intervention for adults with intellectual disabilities and obesity. Br. J. Nutr. 2011, 105, 1553-1562. [CrossRef] [PubMed]

9. Einarsson, I.Ó.; Ólafsson, Á.; Hinriksdóttir, G.; Jóhannsson, E.; Daly, D.; Arngrímsson, S.Á. Differences in physical activity among youth with and without intellectual disability. Med. Sci. Sports Exerc. 2015, 47, 411-418. [CrossRef] [PubMed]

10. Agiovlasitis, S.; Motl, R.W.; Fahs, C.A.; Ranadive, S.M.; Yan, H.; Echols, G.H.; Rossow, L.; Fernhall, B. Metabolic rate and accelerometer output during walking in people with Down syndrome. Med. Sci. Sports Exerc. 2011, 43, 1322-1327. [CrossRef] [PubMed]

11. Dairo, Y.M.; Collett, J.; Dawes, H.; Oskrochi, G.R. Physical activity levels in adults with intellectual disabilities: A systematic review. Prev. Med. Rep. 2016, 4, 209-219. [CrossRef] [PubMed]

12. Sedentary Behaviour Research Network. Letter to the Editor: Standardized use of the terms "sedentary" and "sedentary behaviours". Appl. Physiol. Nutr. Metab. 2012, 37, 540-542. [CrossRef]

13. Katzmarzyk, P.T.; Church, T.S.; Craig, C.L.; Bouchard, C. Sitting time and mortality from all causes, cardiovascular disease, and cancer. Med. Sci. Sports Exerc. 2009, 41, 998-1005. [CrossRef] [PubMed]

14. Van der Ploeg, H.P.; Chey, T.; Korda, R.J.; Banks, E.; Bauman, A. Sitting time and all-cause mortality risk in 222,497 Australian adults. Arch. Intern. Med. 2012, 172, 494-500. [CrossRef] [PubMed]

15. U.S. Department of Health and Human Services. 2008 Physical Activity Guidelines for Americans. Available online: https:/ /health.gov / paguidelines/guidelines/ (accessed on 2 August 2016).

16. Jefferis, B.J.; Parsons, T.J.; Sartini, C.; Ash, S.; Lennon, L.T.; Wannamethee, S.G.; Lee, I.-M.; Whincup, P.H. Does duration of physical activity bouts matter for adiposity and metabolic syndrome? A cross-sectional study of older British men. Int. J. Behav. Nutr. Phys. Act. 2016, 13, 36. [CrossRef] [PubMed]

17. Sardinha, L.B.; Ekelund, U.; dos Santos, L.; Cyrino, E.S.; Silva, A.M.; Santos, D.A. Breaking-up sedentary time is associated with impairment in activities of daily living. Exp. Gerontol. 2015, 72, 57-62. [CrossRef] [PubMed]

18. Bellettiere, J.; Winkler, E.A.H.; Chastin, S.F.M.; Kerr, J.; Owen, N.; Dunstan, D.W.; Healy, G.N. Associations of sitting accumulation patterns with cardio-metabolic risk biomarkers in Australian adults. PLoS ONE 2017, 12, e0180119. [CrossRef] [PubMed]

19. Bartlo, P.; Klein, P.J. Physical activity benefits and needs in adults with intellectual disabilities: Systematic review of the literature. Am. J. Intellect. Dev. Disabil. 2011, 116, 220-232. [CrossRef] [PubMed]

20. Draheim, C.C.; McCubbin, J.A.; Williams, D.P. Differences in cardiovascular disease risk between nondiabetic adults with mental retardation with and without Down syndrome. Am. J. Ment. Retard. 2002, 107, 201-211. [CrossRef]

21. Frey, G.C. Comparison of physical activity levels between adults with and without mental retardation. J. Phys. Act. Health 2004, 1, 235-245. [CrossRef]

22. Temple, V.A.; Frey, G.C.; Stanish, H.I. Physical activity of adults with mental retardation: Review and research needs. Am. J. Health Promot. 2006, 21, 2-12. [CrossRef] [PubMed]

23. Lin, J.D.; Wu, C.L.; Lin, P.Y.; Lin, L.P.; Chu, C.M. Early onset ageing and service preparation in people with intellectual disabilities: Institutional managers' perspective. Res. Dev. Disabil. 2011, 32, 188-193. [CrossRef] [PubMed]

24. World Health Organization. Ageing and Intellectual Disabilities-Improving Longevity and Promoting Healthy Ageing: Summative Report; World Health Organization: Geneva, Switzerland, 2000.

25. Hermans, H.; Evenhuis, H.M. Multimorbidity in older adults with intellectual disabilities. Res. Dev. Disabil. 2014, 35, 776-783. [CrossRef] [PubMed]

26. Lifshitz, H.; Merrick, J.; Morad, M. Health status and ADL functioning of older persons with intellectual disability: Community residence versus residential care centers. Res. Dev. Disabil. 2008, 29, 301-315. [CrossRef] [PubMed] 
27. Berjano Peirats, E.; García Burgos, E. Discapacidad Intelectual y Envejecimiento: Un Problema Social del Siglo XXI; FEAPS: Madrid, Spain, 2010.

28. Melville, C.A.; Oppewal, A.; Schäfer Elinder, L.; Freiberger, E.; Guerra-Balic, M.; Hilgenkamp, T.I.M.; Einarsson, I.; Izquierdo-Gómez, R.; Sansano-Nadal, O.; Rintala, P.; et al. Definitions, measurement and prevalence of sedentary behaviour in adults with intellectual disabilitie-A systematic review. Prev. Med. 2017, 97, 62-71. [CrossRef] [PubMed]

29. Hilgenkamp, T.M.I.; Reis, D.; van Wijck, R.; Evenhuis, H.M. Physical activity levels in older adults with intellectual disabilities are extremely low. Res. Dev. Disabil. 2012, 33, 477-483. [CrossRef] [PubMed]

30. Stanish, H.I.; Draheim, C.C. Assessment of walking activity using a pedometer and survey in adults with mental retardation. Adapt. Phys. Act. Q. 2005, 22, 136-145. [CrossRef]

31. Finlayson, J.; Jackson, A.; Cooper, S.; Morrison, J.; Melville, C.; Smiley, E.; Allan, L.; Mantry, D. Understanding predictors of low physical activity in adults with intellectual disabilities. J. Appl. Res. Intellect. Disabil. 2009, 22, 236-247. [CrossRef]

32. Phillips, A.C.; Holland, A.J. Assessment of objectively measured physical activity levels in individuals with intellectual disabilities with and without Down's syndrome. PLoS ONE 2011, 6, e28618. [CrossRef] [PubMed]

33. Dixon-Ibarra, A.; Lee, M.; Dugala, A. Physical activity and sedentary behavior in older adults with intellectual disabilities: A comparative study. Adapt. Phys. Act. Q. 2013, 30, 1-19. [CrossRef]

34. Coppus, A.M.W. People with intellectual disability: What do we know about adulthood and life expectancy? Dev. Disabil. Res. Rev. 2013, 18, 6-16. [CrossRef] [PubMed]

35. Emerson, E.; Glover, G.; Hatton, C.; Wolstenholme, J. Trends in age-standardised mortality rates and life expectancy of people with learning disabilities in Sheffield over a 33-year period. Tizard Learn. Disabil. Rev. 2014, 19, 90-95. [CrossRef]

36. Spain. Royal Decree Law 1971/1999, December the 23th, Procedure for Recognition, Declaration and Qualification of the Degree of Disability. Available online: http:/ / www.seg-social.es/Internet_1/Normativa/ 097360 (accessed on 30 November 2016).

37. World Health Organization. Obesity: Preventing and Managing the Global Epidemic; World Health Organization: Geneva, Switzerland, 2000.

38. Norton, K.I.; Whittingham, N.; Carter, L.; Kerr, D.; Gore, C.; Marfell-Jones, M. Measurement techniques in anthropometry. In Anthropometrica; Norton Ian, K., Olds, T., Eds.; UNSW: Sydney, Australia, 1996; pp. $22-75$.

39. Jackson, A.S.; Pollock, M.L. Generalized equations for predicting body density of men. Br. J. Nutr. 1978, 40, 497-504. [CrossRef] [PubMed]

40. Jackson, A.S.; Pollock, M.L.; Ward, A. Generalized equations for predicting body density of women. Med. Sci. Sports Exerc. 1980, 12, 175-181. [CrossRef] [PubMed]

41. Siri, W.E. Body composition from fluid spaces and density: Analysis of methods. In Techniques for Measure of Body Composition; Brozek, J., Henschel, A., Eds.; National Academy of Sciences: Washington, DC, USA, 1961; pp. 223-244.

42. Esparza Ros, F. Manual de Cineantropometria, 1st ed.; FEMEDE: Madrid, Spain, 1993; ISBN 84-881000-08-6.

43. Barreira, T.V.; Tudor-Locke, C.; Champagne, C.M.; Broyles, S.T.; Johnson, W.D.; Katzmarzyk, P.T. Comparison of GT3X accelerometer and YAMAX pedometer steps/day in a free-living sample of overweight and obese adults. J. Phys. Act. Health 2013, 10, 263-270. [CrossRef]

44. Connolly, C.P.; Coe, D.P.; Kendrick, J.M.; Bassett, D.R.; Thompson, D.L. Accuracy of physical activity monitors in pregnant women. Med. Sci. Sports Exerc. 2011, 43, 1100-1105. [CrossRef] [PubMed]

45. Kozey, S.L.; Staudenmayer, J.W.; Troiano, R.P.; Freedson, P.S. Comparison of the actigraph 7164 and the actigraph GT1M during self-paced locomotion. Med. Sci. Sports Exerc. 2010, 42, 971-976. [CrossRef] [PubMed]

46. Troiano, R.P.; Berrigan, D.; Dodd, K.W.; Masse, L.C.; Tilert, T.; McDowell, M. Physical activity in the United States measured by accelerometer. Med. Sci. Sports Exerc. 2008, 40, 181-188. [CrossRef] [PubMed]

47. Tudor-Locke, C.; Hatano, Y.; Pangrazi, R.P.; Kang, M. Revisiting “how many steps are enough?”. Med. Sci. Sports Exerc. 2008, 40, S537-S543. [CrossRef] [PubMed]

48. Berlin, J.E.; Storti, K.L.; Brach, J.S. Using activity monitors to measure physical activity in free-living conditions. Phys. Ther. 2006, 86, 1137-1145. [PubMed]

49. Hart, T.L.; Swartz, A.M.; Cashin, S.E.; Strath, S.J. How many days of monitoring predict physical activity and sedentary behaviour in older adults? Int. J. Behav. Nutr. Phys. Act. 2011, 8, 2-7. [CrossRef] [PubMed] 
50. Tudor-Locke, C.; Camhi, S.M.; Troiano, R.P. A catalog of rules, variables, and definitions applied to accelerometer data in the National Health and Nutrition Examination Survey, 2003-2006. Prev. Chronic Dis. 2012, 9, E113. [CrossRef] [PubMed]

51. Cnaan, A.; Laird, N.M.; Slasor, P. Mixed Models: Using the General Linear Mixed Model to Analyse Unbalanced Repeated Measures and Longitudinal Data. In Tutorials in Biostatistics; John Wiley \& Sons, Ltd.: Chichester, UK, 2005; pp. 127-158.

52. Van Schijndel-Speet, M.; Evenhuis, H.M.; van Wijck, R.; van Empelen, P.; Echteld, M.A. Facilitators and barriers to physical activity as perceived by older adults with intellectual disability. Intellect. Dev. Disabil. 2014, 52, 175-186. [CrossRef] [PubMed]

53. Hansen, B.H.; Kolle, E.; Dyrstad, S.M.; Holme, I.; Anderssen, S.A. Accelerometer-determined physical activity in adults and older people. Med. Sci. Sports Exerc. 2012, 44, 266-272. [CrossRef] [PubMed]

54. Peterson, J.J.; Janz, K.F.; Lowe, J.B. Physical activity among adults with intellectual disabilities living in community settings. Prev. Med. 2008, 47, 101-106. [CrossRef] [PubMed]

55. Tudor-Locke, C.; Craig, C.L.; Aoyagi, Y.; Bell, R.C.; Croteau, K.A.; De Bourdeaudhuij, I.; Ewald, B.; Gardner, A.W.; Hatano, Y.; Lutes, L.D.; et al. How many steps/day are enough? For older adults and special populations. Int. J. Behav. Nutr. Phys. Act. 2011, 8, 80. [CrossRef] [PubMed]

56. Loprinzi, P.D.; Cardinal, B.J. Association between biologic outcomes and objectively measured physical activity accumulated in $\geq 10$-minute bouts and $<10$-minute bouts. Am. J. Health Promot. 2013, 27, 143-151. [CrossRef] [PubMed]

57. Matthews, C.E.; Chen, K.Y.; Freedson, P.S.; Buchowski, M.S.; Beech, M.; Pate, R.R.; Troiano, R.P.; Beech, B.M. Amount of time spent in sedentary behaviors in the United States, 2003-2004. Am. J. Epidemiol. 2008, 167, 875-881. [CrossRef] [PubMed]

58. Healy, G.N.; Dunstan, D.W.; Salmon, J.; Cerin, E.; Shaw, J.E.; Zimmet, P.Z.; Owen, N. Breaks in sedentary time: Beneficial associations with metabolic risk. Diabetes Care 2008, 31, 661-666. [CrossRef] [PubMed]

59. Aguilar-Farías, N.; Brown, W.J.; Peeters, G.M.E.E. ActiGraph GT3X+ cut-points for identifying sedentary behaviour in older adults in free-living environments. J. Sci. Med. Sport 2014, 17, 293-299. [CrossRef] [PubMed]

60. Jefferis, B.J.; Sartini, C.; Shiroma, E.; Whincup, P.H.; Wannamethee, S.G.; Lee, I.-M. Duration and breaks in sedentary behaviour: Accelerometer data from 1566 community-dwelling older men (British Regional Heart Study). Br. J. Sports Med. 2015, 49, 1591-1594. [CrossRef] [PubMed]

61. Shiroma, E.J.; Freedson, P.S.; Trost, S.G.; Lee, I.-M. Patterns of accelerometer-assessed sedentary behavior in older women. JAMA 2013, 310, 2562-2563. [CrossRef] [PubMed]

62. Powell, K.E.; Paluch, A.E.; Blair, S.N. Physical activity for health: What kind? How much? How intense? On top of what? Annu. Rev. Public Health 2011, 32, 349-365. [CrossRef] [PubMed]

63. Carmeli, E.; Merrick, J.; Imam, B.; Levy, R. Exercises and sports participation in healthy older adults with intellectual disability-A pilot study. Health 2012, 4, 769-774. [CrossRef]

64. Dunstan, D.W.; Kingwell, B.A.; Larsen, R.; Healy, G.N.; Cerin, E.; Hamilton, M.T.; Shaw, J.E.; Bertovic, D.A.; Zimmet, P.Z.; Salmon, J.; et al. Breaking up prolonged sitting reduces postprandial glucose and insulin responses. Diabetes Care 2012, 35, 976-983. [CrossRef] [PubMed]

65. Agiovlasitis, S.; Beets, M.W.; Motl, R.W.; Fernhall, B. Step-rate thresholds for moderate and vigorous-intensity activity in persons with Down syndrome. J. Sci. Med. Sport 2012, 15, 425-430. [CrossRef] [PubMed]

66. Hinckson, E.A.; Curtis, A. Measuring physical activity in children and youth living with intellectual disabilities: A systematic review. Res. Dev. Disabil. 2013, 34, 72-86. [CrossRef] [PubMed]

(C) 2017 by the authors. Licensee MDPI, Basel, Switzerland. This article is an open access article distributed under the terms and conditions of the Creative Commons Attribution (CC BY) license (http://creativecommons.org/licenses/by/4.0/). 